This item was submitted to Loughborough's Research Repository by the author.

Items in Figshare are protected by copyright, with all rights reserved, unless otherwise indicated.

\title{
Vehicle internal design improvement guidelines by using the computational pregnant occupant model 'expecting'
}

PLEASE CITE THE PUBLISHED VERSION

http://dx.doi.org/10.1504/IJHFMS.2010.040272

\section{PUBLISHER}

(C) Inderscience

\section{VERSION}

AM (Accepted Manuscript)

\section{PUBLISHER STATEMENT}

This work is made available according to the conditions of the Creative Commons Attribution-NonCommercialNoDerivatives 4.0 International (CC BY-NC-ND 4.0) licence. Full details of this licence are available at: https://creativecommons.org/licenses/by-nc-nd/4.0/

\section{LICENCE}

CC BY-NC-ND 4.0

\section{REPOSITORY RECORD}

Acar, B. Serpil, and Senay Mihcin. 2019. "Vehicle Internal Design Improvement Guidelines by Using the Computational Pregnant Occupant Model 'expecting'". figshare. https://hdl.handle.net/2134/25645. 


\title{
Vehicle Internal Design Improvement Guidelines by Using the Computational Pregnant Occupant model 'Expecting'
}

\author{
B Serpil Acar* and S Mihcin \\ Department of Computer Science / Research School of Informatics, \\ Loughborough University, LE11 3TU, UK
}

\begin{abstract}
New interior designs for vehicles may improve the safety of pregnant occupants without compromising the safety of non-pregnant occupants. The objective of this study is to investigate the implications of the steering wheel unit orientation by using 'Expecting', the Computational Pregnant Occupant Model developed at Loughborough University. Three steering column angles and three steering wheel angles are modelled in a subcompact mini-car interior in MADYMO. A standard 3-point seat belt and an airbag are used as restraint systems. The strain values at the placental location of the uterus of 'Expecting' for frontal impacts with 15, 30, $45 \mathrm{kph}$ are predicted for various steering wheel unit configurations and the resulting distance between the steering wheel unit and the abdomen and sternum of 'Expecting'. Recommendations are made to improve safety.
\end{abstract}

Keywords: Vehicle design, safety, modelling, pregnant woman, fetus, crash, Expecting, steering wheel, steering column. 


\section{INTRODUCTION}

Pregnant women are likely to be vehicle drivers or passengers during some or all stages of their pregnancy. The most recent statistical data show that every year, approximately 750,000 full-term pregnancies are recorded in the UK alone. Increasing number of women is driving everyday and consequently increasing number of pregnant women is being exposed to automobile accidents. Motor vehicle crashes are the leading cause of accidental fetal mortality and placental abruption has been shown to account for $50 \%$ to $70 \%$ of all fetal losses following motor vehicle crashes (Pearlman et al,1990). The safety of non-pregnant people improved over the years due to research, crash tests, design decisions and implementations. Research in advanced modelling of pregnant women is hoped to help making significant changes in the design of cars to improve safety for all, including pregnant women.

Physical models commonly represent humans in crash tests to simulate real life accidents (FMVSS, 2006). $50^{\text {th }}$ percentile male Anthropomorphic Test Device (ATD) is the most widely used representation. $5^{\text {th }}$ percentile female model is also increasingly used in crash tests. Acar and Weekes (2005) highlights the importance of the physiological changes in the female body during pregnancy. In particular, during the third trimester of pregnancy, with the changes in the chest, abdomen and thigh areas pregnant women form a new population which would be excluded from typical designs for men and non-pregnant women (Acar and Weekes, 2006).

Earlier proximity studies (with non-pregnant subjects) include Segui-Gomez et al (1999) that observed a considerable misconception of the drivers' 'proximity to the steering wheel perception' and Manary et al (1998) that predicted driver head and thorax to the steering wheel. Both considered $254 \mathrm{~mm}$ (10 inches) distance between the sternum and the steering wheel centre as safe.

The fetal mortality in road traffic accidents are perceived as hidden epidemics (Weiss, 2006). A study of the pregnant drivers' proximity to steering-wheel rim over the course of their pregnancies was conducted by Klinich et al (1999). Moorcroft et al (2003) generated a computer model of a 30 week pregnant occupant model (without fetus) to assess the risk of injury in frontal crashes. Driver position is observed to be the highest risk position and the peak uterine strain increases significantly from passenger to driver position due to presence of steering wheel unit (Moorcroft et al, 2004). Acar and Weekes (2004) collected the pregnant women anthropometric data and developed an information resource system in "Automotive Design: Incorporating the Needs of Pregnant Women" project based at Loughborough University. Acar and Weekes (2005) found that $9 \%$ of pregnant women were seated with their abdomen nearly touching or in contact with the steering wheel.

Acar and Weekes' anthropometric data sets are used to develop the 3D computational model 'Expecting' by Acar and van Lopik (2009) at Loughborough University. The pregnant woman model is generated in a generic vehicle interior consisting of a seat, vehicle floor, pedals and steering wheel. 'Expecting' is used in various impact severity crash simulations, the 
strains at the placental area of the uterus were calculated along with the abdominal deformations. It is concluded that having an airbag and the correctly worn seat belt provides the best protection for fetuses. Acar and Esat (2010) found that this also provides the best protection for pregnant women themselves.

Motozawa et al (2007) investigated the forward displacement of the pregnant abdomen which results in the likelihood of contact with the interior parts of the automobile by using an ATD and their measurements also confirm that the peak abdominal pressure is at the point where the ATD comes in contact with the steering wheel.

In this study, interior design of cars, in particular, the implications of the steering wheel unit orientation on pregnant women are investigated. 'Expecting' model is used as the driver of a subcompact mini-car. Various impact severity crash scenarios are simulated to investigate the strain values at the utero-placental interface for nine combinations of the steering column angle and steering wheel angle for frontal impacts.

\section{METHODOLOGY}

'Expecting', a computational model of pregnant woman, is developed at Loughborough University by Acar and Van Lopik, 2009 (Figure 1). Expecting is created by incorporating a finite element uterus with a placenta, and with a multi-body model of a 38 week old fetus in uterus into the $5^{\text {th }}$ percentile female model of MADYMO version 6.2. The model is also altered to have sitting anthropometry of $38^{\text {th }}$ week of pregnant woman. The validation process excludes the living or cadaver pregnant subjects due to ethical issues. 'Expecting' is validated against rigid-bar impact and belt loading tests suggested by Hardy et al. (2001). The ability of 'Expecting' to predict fetal outcome results is further demonstrated by comparing the simulation results with directly comparable real life accident results as explained in detail in Acar and van Lopik, 2009. 'Expecting' is used in various crash simulations to investigate pregnant woman's dynamic response for frontal impacts with and without the restraints of three point seat belt and an airbag in a generic car interior in Acar and Esat, 2010. 


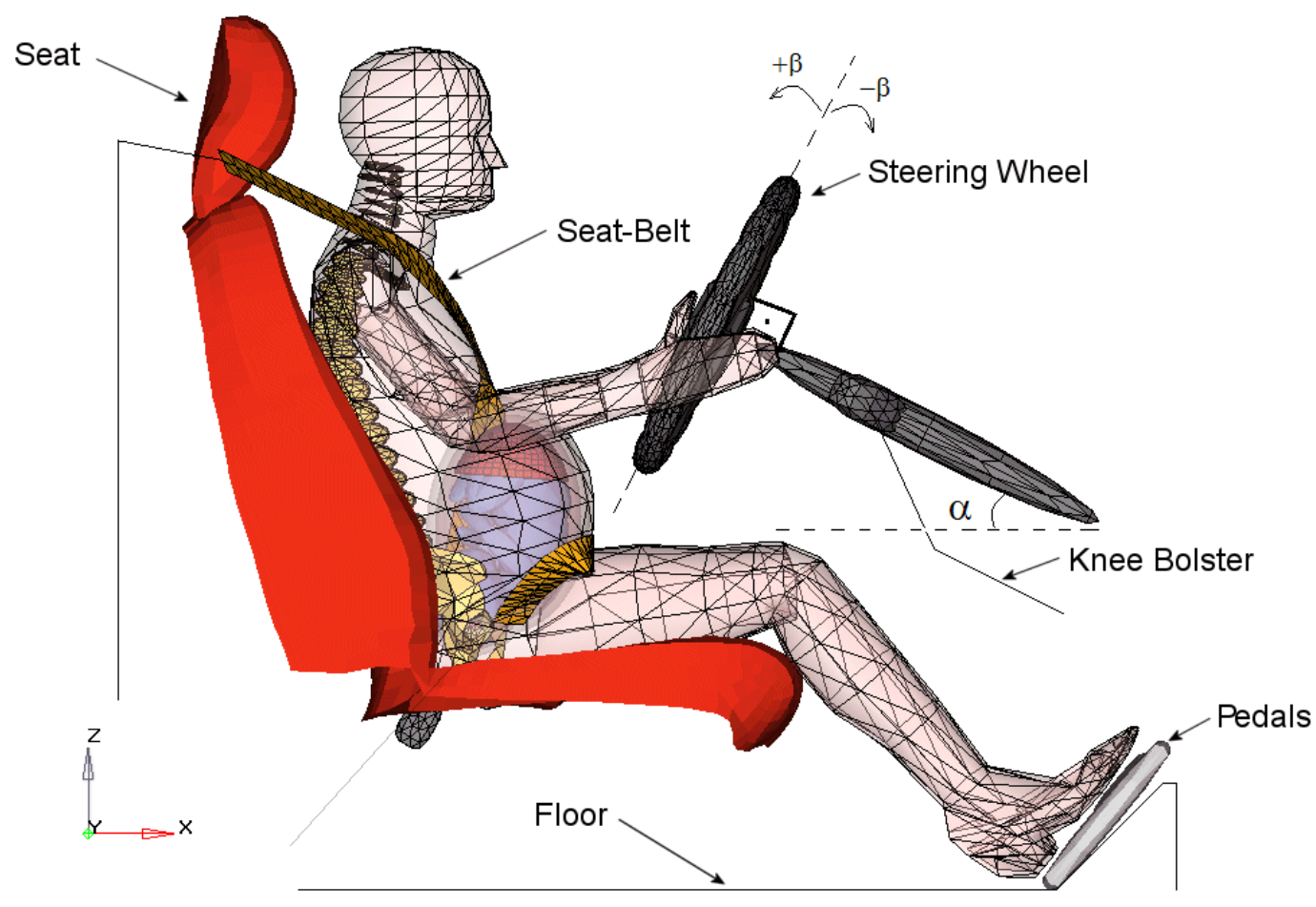

Figure 1 'Expecting in a generic car environment

The 3-point seat belt with a width and thickness of $50 \mathrm{~mm}$ and $1 \mathrm{~mm}$ respectively and the standard MADYMO driver airbag model positioned at the centre of the steering wheel are used in 'Expecting'. Half-sine wave acceleration pulse of 120 ms duration is used in crash simulations where no seatbelt pre-tensioners are fired and the airbag is set to trigger after $15 \mathrm{~ms}$ of the acceleration pulse. Seat pan angle is taken as $10^{\circ}$ to the horizontal. Seat back angle is $14.8^{\circ}$ with respect to the vertical axis in the seat model. In this study the horizontal distance between the car speed control plane (accelerator, brake, clutch pedals) and the front-end of the seat is taken as $485 \mathrm{~mm}$ for Expecting's proper driving position. The interior surfaces of the bolsters are represented as rigid body ellipsoids connected to this plane.

In this study, in order to investigate the effects of specific car features on pregnant driver, 'subcompact mini car' (SC) group, a popular choice with women in the child-bearing age, is chosen as the vehicle. The parameters of interior features of the cars are classified in three subgroups: control units (CU), interior plane (IP) and occupant space (OS). Subcompact mini car values (SCCU, SCIP and SCOS values) are used to generate the car model in MADYMO.

Pregnant drivers are generally advised to adjust their seats therefore they can sit far away from the steering wheel. However this is not always practical since the pregnant driver needs to reach the control pedals. The distance between pregnant driver and the steering wheel can be altered without changing the driver's posture by changing the steering column angle and the steering wheel angle as they are adjustable in some cars. 
The angle of the steering column and the angle of the steering wheel are usually not adjustable in SC cars. In order to investigate the role of the changes in steering column angle and the steering wheel angle on safety of the fetus, 'Expecting' simulations are conducted as follows: Nine combinations of steering column and steering wheel are considered. The steering column angle, $\alpha$, is measured initially as 27 with respect to the horizontal axis. Three values for $\alpha$, are taken as 22, 27 and 32. Further conditions where the steering wheel itself is rotated around the steering column in the sagittal plane are also considered. Three values for this rotation, $\beta$, are taken as 15 (for the top of the steering wheel pulled towards the driver) 0 (where the steering column is perpendicular to the steering wheel plane), and -15 (for the top of the steering wheel pushed away from the driver). Figure $2(a, b, c)$ shows the three $\alpha$ values $(22,27$ and 32) when $\beta=0$, and Figure $3(a, b, c)$ shows three $\beta$ values $(15,0$ and -15$)$ when $\alpha=27$. Nine combinations of the steering column and the steering wheel are shown in Figure 4.

Placental abruption is known to account for more than half of fetus deaths in motor vehicle related injuries. In this study, strain levels in uterus at uteroplacental interface (UPI) are collected to investigate the possibility of placental abruption. The threshold strain value for the occurrence of placental abruption is widely accepted to be 0.60 at the UPI (Rupp et al, 1990). Strains at the UPI are calculated for each combination of the $\alpha$ and $\beta$ for the three crash severity cases represented by 15,30 and 45 kph crashes.

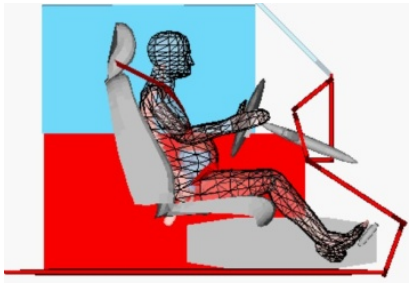

(a) $\alpha=22, \beta=0$

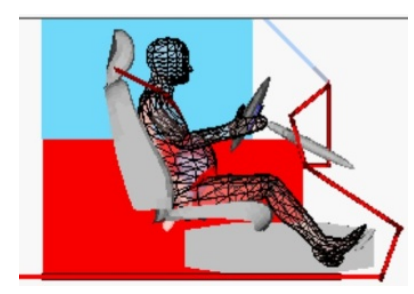

(b) $\alpha=27, \beta=0$

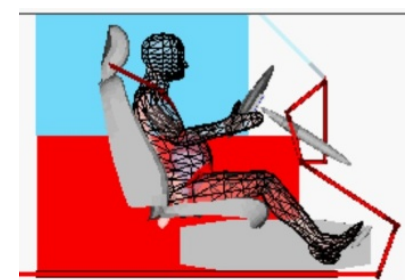

(c) $\alpha=32, \beta=0$

Figure 2 'Expecting' in a subcompact mini car for three steering column angle $\alpha$, when the steering wheel angle $\beta=0$.

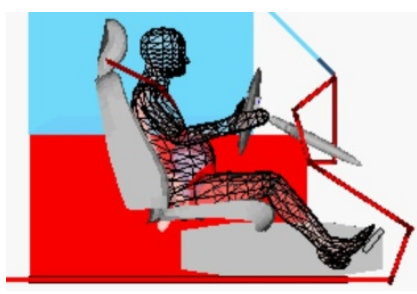

(a) $\alpha=27, \beta=15$

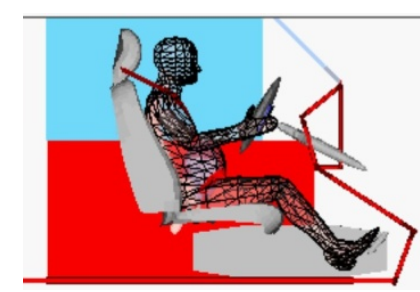

(b) $\alpha=27, \beta=0$

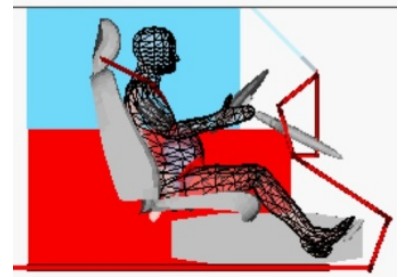

(c) $\alpha=27, \beta=-15$

Figure 3 'Expecting' in a subcompact mini car for three steering wheel angle $\beta$, when the steering column angle $\alpha=27$. 


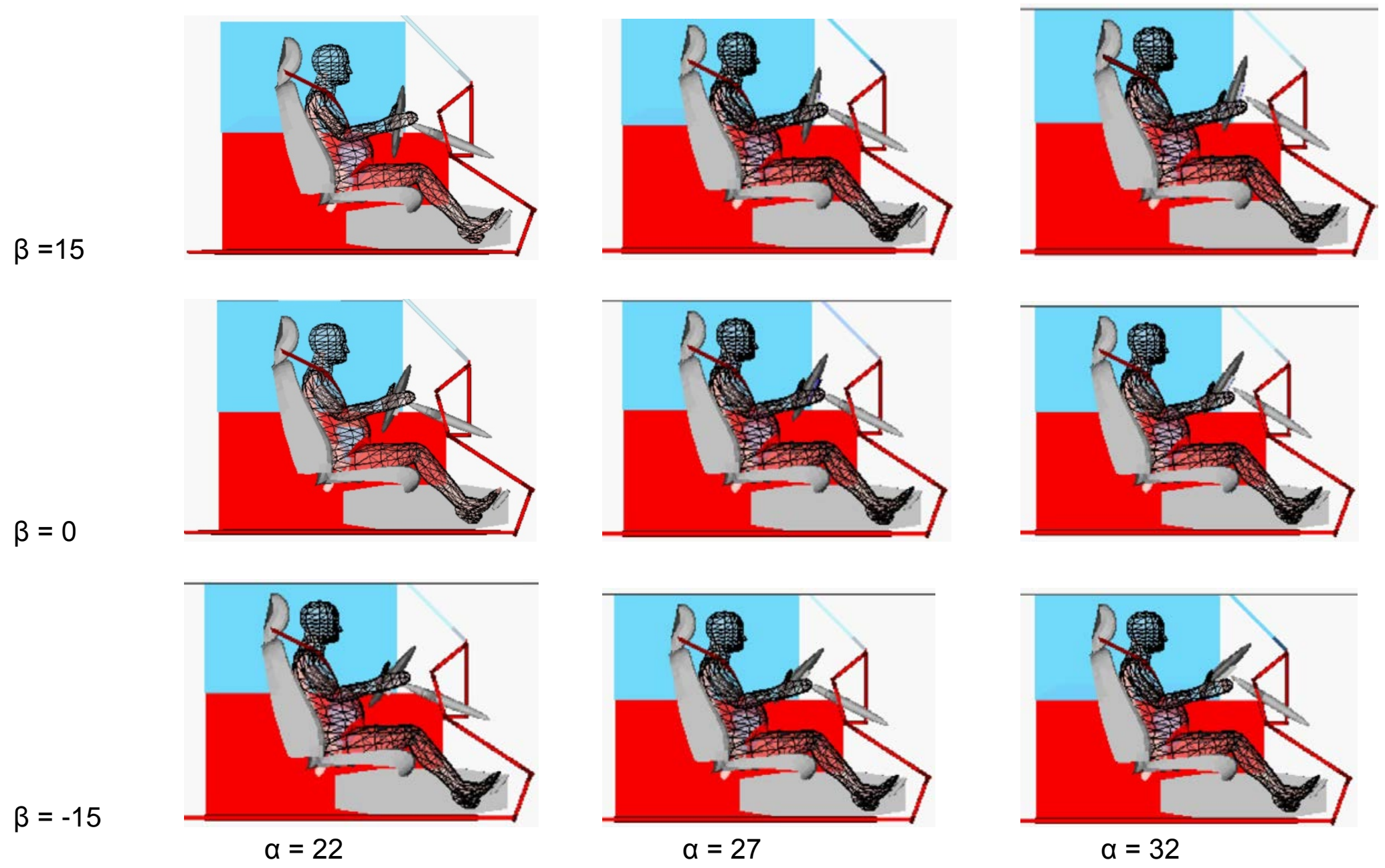

Figure 4 'Expecting' in a subcompact mini car for nine combinations of steering column angle $\alpha$, and steering wheel angle 


\section{RESULTS}

The results of this study, the strain values at the Utero-Placental Interaction (UPI) for twenty seven simulations in MADYMO are listed in Table 1.

Table 1 Maximum strain levels at UPI for different values of the steering column angle $(\alpha)$, steering wheel angle $(\beta)$ and the frontal crash speed .

\begin{tabular}{|c|c|c|c|c|c|c|}
\hline $\begin{array}{l}\text { Steering } \\
\text { column angle }\end{array}$ & $\begin{array}{c}\text { Steering } \\
\text { wheel angle }\end{array}$ & \multicolumn{2}{|c|}{$\begin{array}{l}\text { Distance between steering } \\
\text { wheel and 'Expecting' 's }\end{array}$} & \multicolumn{3}{|c|}{$\begin{array}{c}\text { Strains (\%) at UPI } \\
\text { when } \\
\Delta \mathrm{v} \text { is }\end{array}$} \\
\hline$\alpha$ & $\beta$ & $\begin{array}{l}\text { Abdomen } \\
\mathrm{d}_{1}{ }^{*}(\mathrm{~mm})\end{array}$ & $\begin{array}{l}\text { Sternum } \\
d_{2}^{* \star}(\mathrm{mm})\end{array}$ & $\begin{array}{c}15 \\
\mathrm{kph}\end{array}$ & $\begin{array}{r}30 \\
\mathrm{kph}\end{array}$ & $\begin{array}{r}45 \\
\mathrm{kph}\end{array}$ \\
\hline \multirow{3}{*}{22} & 15 & 97 & 251 & 18 & 34 & 72 \\
\hline & 0 & 56 & 258 & 43 & 60 & 101 \\
\hline & -15 & 38 & 270 & 58 & 78 & - \\
\hline \multirow{4}{*}{27} & & & & & & \\
\hline & 15 & 105 & 265 & 12 & 30 & 76 \\
\hline & 0 & 66 & 276 & 12 & 25 & 77 \\
\hline & -15 & 60 & 295 & 31 & 34 & - \\
\hline \multirow{3}{*}{32} & 15 & 130 & 291 & 13 & 21 & 74 \\
\hline & 0 & 111 & 307 & 13 & 22 & \#53 \\
\hline & -15 & 149 & 321 & 12 & 20 & \# 41 \\
\hline
\end{tabular}

- The impact is so severe, the model becomes unstable.

* $\mathrm{d}_{1}$ : horizontal distance between the low rim of the steering wheel and the body

${ }^{* *} d_{2}$ : the distance between the center of the steering wheel and the sternum

\# airbag would deploy towards the head against advise by the authorities.

When the results of the crash simulations at 15, 30 and $45 \mathrm{kph}$ are observed where the steering column and steering wheel are at any position; it is evident that the strain at the UPI increases with crash severity and is over the threshold at $45 \mathrm{kph}$ for most of the combinations. Default position of the steering wheel unit ( $\alpha=27, \beta=0)$ gives UPI strains of $12 \%$ for $15 \mathrm{kph}, 25 \%$ for $30 \mathrm{kph}$ and $77 \%$ for $45 \mathrm{kph}$ crashes. This suggests that a $45 \mathrm{kph}$ crash would carry a high risk for the placental abruption and hence fetus death as it is over the threshold value $60 \%$.

In order to investigate whether the adjustment of the steering wheel angle makes any difference, the result for the default position is compared with the results where the steering column angle is kept as $\alpha=27$, and the steering wheel angle is adjusted to $\beta=15$ and -15 . Pulling the top rim of the steering wheel towards the pregnant driver $(\beta=15)$ seems to cause very little difference on the UPI strains at these speeds and does not have any effect on the hazard status. However, when the top rim is pushed, even though the hazard status is unchanged, it seems to cause increase on the strains and the model becomes unstable for $45 \mathrm{kph}$ at this combination, representing severe damage. 
When the steering column angle is changed $+/-5$ degrees from its default position and the steering wheel angle with respect to the steering column is kept as perpendicular to the steering column, i.e. $\alpha=22$ and $32, \beta=0$; some changes in the hazard status of the UPI strains can be observed.

Lowering the steering column $(\alpha=22)$, can cause huge increments on the strains up to the threshold level even for $30 \mathrm{kph}$. However increasing the steering column angle with the horizontal axis lowers the strain level below the threshold at severe crashes and keeps the strains at about very similar level for 15 and $30 \mathrm{kph}$. Full discussion about this case can be found in the 'Discussions' section.

When all the steering wheel angle adjustments are considered for all the steering column angles, overall analysis of 27 cases show that low UPI strain levels are observed during the crashes at $15 \mathrm{kph}$ and $30 \mathrm{kph}$ with both 27 and 32 degrees of steering column angle. With the 22 degrees of steering column, UPI strains are generally higher than corresponding strains for other steering column angles. However the strains are still on the 'safer-side' at $15 \mathrm{kph}$ when $\beta$ is 15 or 0 and around the threshold when $\beta=-15$ whereas at $30 \mathrm{kph}$ it suggest placental abruption both at $\beta=0$ and -15 .

A severe crash is presented at $45 \mathrm{kph}$. Steering column angles of 22 and 27 degrees give well above the threshold strain values for each $\beta$ value whereas 32 degree gives lower strains, still being above the threshold value when the top rim of the steering wheel is pulled towards the driver. However low UPI must not be misleading and these cases will be discussed further in the next section.

Table 1 also shows the horizontal distance between (usually the abdomen of) 'Expecting' and the low rim of the steering wheel and the distance between the centre of the steering wheel and the sternum of 'Expecting' for each combination of $\alpha$ and $\beta$. The importance of positioning will also be discussed in the next section.

\section{DISCUSSIONS}

As a general safety rule, all occupants need to wear their seatbelts and wear them correctly. Pregnant occupants are not exempt. The correct seat belt position for pregnant women, described by the Department for Transport (DFT) in the UK (2003), and American College of Obstetrics and Gyneacology (ACOG) (1999) and National Highway Traffic Safety Administration (NHTSA) in the US (2002) is 'the lap strap should go across the hips, fitting comfortably under the 'bump', while the diagonal strap should be placed between the breasts and around the bump'. Research by Acar and Van Lopik (2009) has shown that the fetus is at increased risk during a collision if the seat belt is not worn, or only the lap belt or shoulder belt is used.

NHTSA (2009) also recommends all drivers to sit as far from the airbag as possible and to move the driver's seat rearward to allow at least 10 inches ( $254 \mathrm{~mm}$ ) between the centre of the steering wheel and the driver's sternum. 
When women get pregnant they do not alter their fore-aft position due to the need to reach the control pedals. Given that the sitting position remains the same, the distance between the driver and the steering wheel decreases during pregnancy due to protrusion around the abdominal region.

At the moment the only possible way of increasing the distance between pregnant driver and the steering wheel unit without changing the driver's position is changing the steering unit position. In this study, the computational pregnant occupant model, 'Expecting', is positioned as the driver of a subcompact mini-car. Crash scenarios are simulated to investigate the strains at the placental location (hence the safety of the fetus) for 9 combinations of the steering column angle and steering wheel angle in frontal impact scenarios.

The results, confirm that that the crash severity is the most important factor in the strains at the placental location. For severe crashes at $45 \mathrm{kph}$ the strains at UPI is over the threshold in all combinations except two combinations where $\alpha=32$ and $\beta=0$ or -15 . However these combinations cannot be advised since they are extreme cases which would result in the airbag deploying towards the head rather than the chest even though the steering wheel would miss the 'bump'.

For the moderate crashes, the angle of the steering column and the steering wheel can have a combined effect on the strain values at UPI. The close abdominal proximity to the steering wheel, through the steering wheel and steering column tilt, results in the borderline/higher than the threshold UPI strains. The combination where $\alpha=22$ and $\beta=-15$ can be given as an example to this where the resultant distance to the abdomen is as little as 38 $\mathrm{mm}$ and the strain levels are 58\% and $78 \%$ for crash speeds of $15 \mathrm{kph}$ and $30 \mathrm{kph}$ respectively. The distance of the steering wheel to the sternum $\left(\mathrm{d}_{2}\right)$ at that combination is $270 \mathrm{~mm}$, that is above the advised 10 inches (254 mm) and yet clearly not a safe distance for pregnant driver. $d_{2}$ also reaches the greatest values at $\alpha=32$ however it cannot be advised due to direction of the airbag as discussed above. Therefore this research suggests that $d_{2}$, in general, should not be used as a safety metric for pregnant drivers.

\section{CONCLUSIONS}

In this paper, a typical subcompact mini car model, a popular type of car with young women is generated where the back of the seat pan height is fixed at $257 \mathrm{~mm}$. 'Expecting' represents a 38 week pregnant woman whose stature represents $5^{\text {th }}$ percentile women.

In our simulations the distance between the sternum of 'Expecting' to the (centre of) the steering wheel varies between 251 to $321 \mathrm{~mm}$. As seen above larger distance between the sternum of pregnant woman and the steering wheel centre does not necessarily confirm safety and should not be used as a metric for safety. However, it appears that the steering wheel's lower rim proximity and the angle are important factors in safety.

This study investigates the consequences of changing proximity through the combined change in the steering column angle $\alpha$ and steering wheel angle $\beta$ on safety for pregnant driver. It would not be wise to advise a specific $\alpha$ or $\beta$ 
value since the resulting strains at the placental location also depend on the seat height, make and model of the cars and the abdominal height which would depend on the individual pregnancy.

The conclusions of what this study suggests for the safety of fetus can be summarised as follows:

- Pregnant women should drive slowly. The strains at UPI increase with crash severity and present high risks of fetus mortality;

- Pregnant women should be made aware of the possible adjustments of interior features of the cars, such as the height and fore-aft positioning of the seat, and steering wheel unit adjustments so that the horizontal distance between the abdomen and the steering wheel can be maximised;

- The distance of the steering wheel to the sternum should not be used as a safety metric for pregnant drivers.

The conclusions also support the earlier recommendations of Acar and Weekes (2005) that

- Pregnant women should be educated to wear their seatbelts correctly;

- The motor manufacturers should be encouraged to consider design features such as

o adjustable or extendable pedals,

o adjustable steering wheel unit

as 'standard' in cars that are popular with the women of child-bearing age.

- The motor manufacturers should also be encouraged to consider futuristic design features and alternative driving methods, such as drive-by-wire.

This research suggests that sitting very close to the steering wheel is clearly not a good idea. Acar and Weekes (2006) found that 9\% of pregnant women were seated with their abdomen nearly touching or in contact with the steering wheel. In such cases pregnant women can be recommended not to drive.

\section{ACKNOWLEDGEMENTS}

The authors would like to thank the Engineering and Physical Sciences Research Council (EPSRC) and Innovative Manufacturing and Construction Research Centre (IMCRC) for funding this research. Advanced Simtech is also acknowledged for reduced academic licence fees for MADYMO. 


\section{REFERENCES}

Acar B S and Weekes A M (2004) 'Designing for safety during pregnancy through a system for automotive engineers', International Journal of Crashworthiness, Vol. 9, pp 625-632.

Acar B S and Weekes A M (2005) 'Design guidelines for pregnant occupant safety' Proc Institution of Mechanical Engineers, Part D: Journal of Automobile Engineering, Vol. 219, No. 7, pp 857-867.

Acar B S and Weekes A M (2006) 'Measurements for pregnant driver comfort and safety'. International Journal of Vehicle Design, Vol. 42, No.1, pp 101-118.

Acar, B. S. and van Lopik D.(2009) 'Computational pregnant occupant model, 'Expecting', for crash simulations', Proc Institution of Mechanical Engineers, Part D: Journal of Automobile Engineering, Vol. 223, pp. 891-902.

Acar B S and Esat V (2010) 'A Computational Investigation on Seat Belt Use for Pregnant Drivers in Airbag Equipped Automobiles' to appear in International Journal of Human Factors Modelling and Simulation.

American College of Obstetrics and Gynecology (ACOG), (1999) 'Obstetric Aspects of Trauma Management'. WASHINGTON DC: ACOG (REPORT 251).

DEPARTMENT FOR TRANSPORT (DFT), (2003) 'Seat belts and child restraints'. London: Department for Transport (DFT) UK (T/INF/251).

FMVSS (2006) Standard No. 208, Occupant crash protection, D. NHTSA, Editor. October 2006.

Klinich, K.D., Schneider, L.W., Eby, B., Rupp. J., and Pearlman, M.D.(1999) 'Seated anthropometry during pregnancy', UMTRI-99-16.

MADYMO HUMAN MODELS MANUAL.(2005) 'Facet Occupant Models' TNO Automotive, pp221-253.

Manary M A,Flannagan C A C,Reed M P, Lawrence W S. (1998) 'Predicting Proximity of Driver Head and Thorax to the Steering Wheel', UMTRI-98-S1-O11.

Moorcroft D, Stitzel J, Duma S.M., Duma G. (2003) 'A Finite Element and multi-body model of the pregnant female occupant for the analysis of restraint effectiveness', SAE Transactions, 2003-01-157, Vol 112, No 6, pp62-70.

Moorcroft D, Stitzel J, Duma S.M., Duma G. (2004) 'The effect of pregnant occupant position and belt placement on the risk of fetal injury', SAE Transactions, 2004-01-0324, Vol 112, No 6, pp62-70.

Motozawa $Y$ and Hitosugi M. (2007) 'Experimental analysis of abdominal pressure of pregnant occupants during automotive collisions using an AF5 pregnant dummy' 20th International Technical Conference on the Enhanced Safety of Vehicles. Lyon, France.

NATIONAL HIGHWAY TRAFFIC SAFETY ADMINISTRATION (NHTSA) (2002) 'Should pregnant women wear seatbelts'. Washington DC: National Highway Traffic Safety Administration (NHTSA) USA, (DOT HS 809 506).

NHTSA Consumer Information Websites (2009) http://www.nhtsa.dot.gov/staticfiles/DOT/NHTSA/Communication\%20\&\%20 Consumer\%20Information/Articles/Associated\%20Files/BUA_PregnancyNH TSAchange.pdf. Accessed in October 2009.

Pearlman, M.D., Tintinalli J.E., and. Lorenz R.P. (1990) 'Blunt trauma during pregnancy'. New England Journal of Medicine, Vol. 323, No. 23, pp. 16091613. 
Rupp, J. D., Klinich, K. D., Moss, S., Zhou, L., Pearlman, M. D., and Schneider, L.W. (2001) 'Development and testing of a prototype pregnant abdomen for the small female Hybrid III small female ATD'. Stapp Car Crash Journal, Vol. 45, pp. 61-78.

Segui-Gomez M, Levy J, Roman H, Thompson K M, McCabe K, Graham J D. (1999) 'Driver distance from the steering wheel: perception and objective measurement', American Journal of Public Health, Vol 89, No 7, pp11091111.

Weiss, H.(2006) 'Hidden epidemic of maternal, fetal and neonatal mortality and injury from crashes - A case of societal neglect?' Transportation Research Record: Journal of the TRB, No.1956 pp. 133-140. 